\title{
Iron deficiency anemia: current strategies for the diagnosis and management
}

Zühre Kaya ${ }^{1}$

${ }^{1}$ The Pediatric Hematology Unit of the Department of Pediatrics, Medical School of Gazi University, Ankara, Turkey

\section{Abstract}

Iron deficiency is one of the commonest nutritional deficiencies in the world. It is multifactorial and may be caused by lack of intake, blood loss and intestinal causes. Clinical features are highly variable, and most patients are asymptomatic. Typical laboratory features of iron deficiency anemia (IDA) include a hypochromic microcytic anemia, low serum iron level, high total iron binding capacity, low serum ferritin level. Usefulness of monitoring serum transferrin receptor level (sTfR) and hepcidin for identifying IDA have been examined in a few studies. Available data suggest that sTfR can potentially become a valuable tool for regular testing of patients in the future. Despite IDA is easily corrected with iron therapy, establishing the cause can be difficult, particularly in cases caused by disorders of iron transport. Education for clinician needs to focus on increasing awareness of the importance of failure respond to iron supplementation. The aim of this review was to outline the current strategies for the diagnosis and management of IDA in the light of the latest reports.

\section{Keywords}

Iron deficiency anemia, Homeostasis, Iron supplementation 


\section{Introduction}

Iron deficiency is still the most frequently nutritional deficiencies globally [1,2]. Iron deficiency can affect all age groups, but infants and young children are most at risk, particularly in the developing countries. Iron deficiency anemia (IDA) is common in young children and in pregnant women with a prevalence ranging from $15 \%-40 \%$ according to the various studies and definition used [1-5]. According to World Health Organization report, iron deficiency anemia accounts for approximately $50 \%$ of all anemia cases [1].

This review summarizes the current knowledge on IDA, with a particular focus on iron metabolism in regard to its pathogenesis and clinical features as well as to its diagnosis and treatment.

\section{Iron metabolism and homeostasis}

Most dietary iron is present in food of animal origin, including red meat, fish and dairy products. The average daily iron intake is $1-2 \mathrm{mg}$ in a healthy person. Dietary iron can exist in either organic or heme iron as soluble ferrous (reduced $\mathrm{Fe}^{++}$) form, which is found in animal sources, or inorganic or nonheme iron as insoluble ferric (oxidized $\mathrm{Fe}^{+++}$) form, which is found in plant sources [6-10].

The absorption of dietary iron by the enterocyte is a complex process (Figure 1).

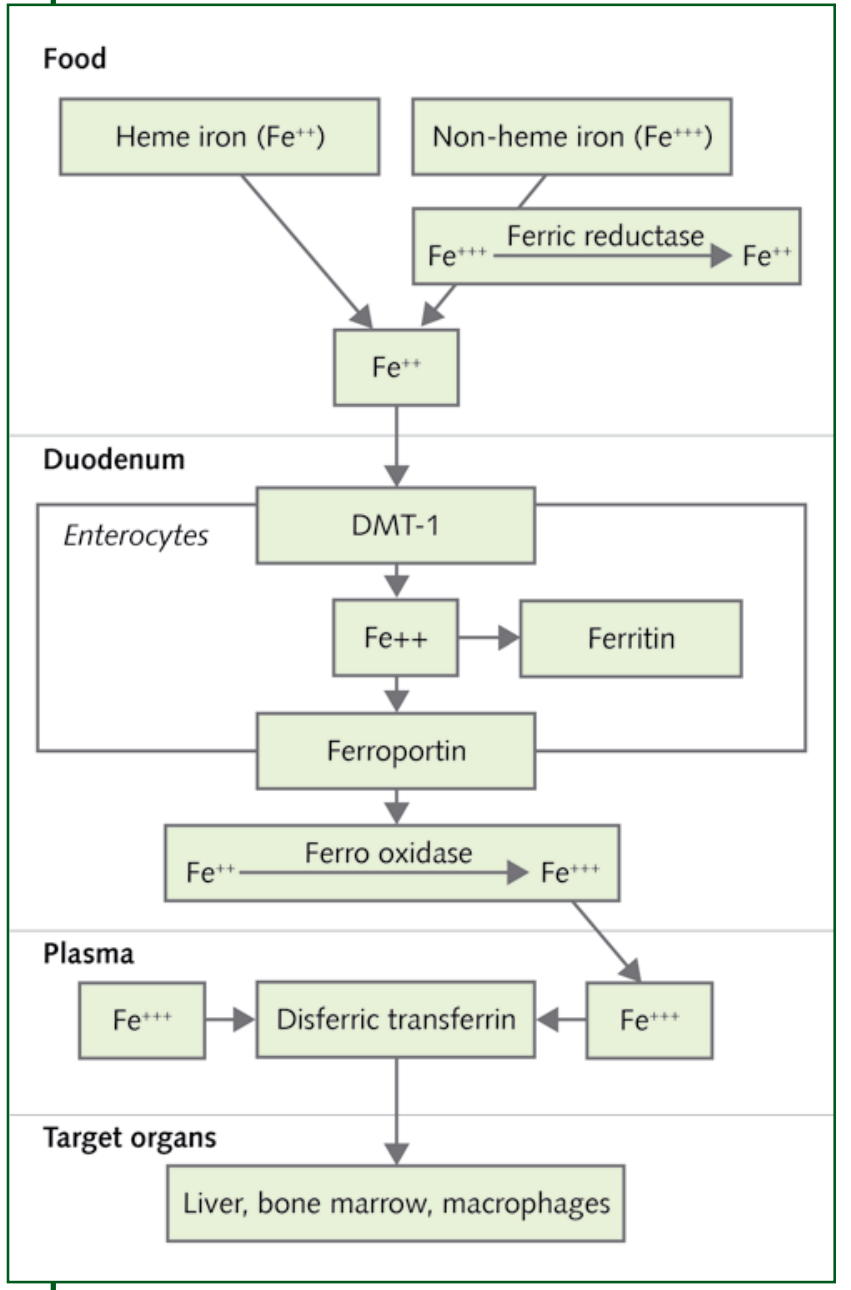

Figure 1. Iron metabolism and homeostasis
In brief, dietary ferrous iron is taken up directly from the apical surface of the enterocyte into the cytoplasm by the DMT-1 (divalent metal transporter) protein [11]. However, non-heme iron is not directly recognized by these protein. It must be reduced to the ferrous form by ferric reductase and then binds to DMT-1 receptors in the apical brush border of enterocytes prior to duodenal absorption. Once intracellular ferrous iron can be either stored as ferritin or exported across the basolateral surface of the enterocytes into the circulation by ferroportin. It must be oxidized to the ferric form by ferro-oxidase before releasing from enterocyte. In the circulation, ferric iron is carried out by transferrin, which facilitates cellular iron uptake through its interaction with specific transferrin membrane receptors (sTfR). Approximately $80 \%$ of sTfR are located in the erythroid precursors in bone marrow. Iron is an essential element that functions as a major component, about $70 \%$, of oxygen carrying hemoglobin and a small amount of redox enzymes (5\%) in cellular metabolism and most of the rest (25\%) is stored as ferritin and hemosiderin in target organs. Free iron from senescent red cells, phagocytosed by reticuloendothelial system is bound to transferrin, and recycled. 
In this context, hepcidin is a small peptide hormone predominantly synthesized in the liver and is the key regulator of systemic iron homeostasis. Hepcidin plays a critical role in regulating systemic iron levels by inhibiting intestinal iron absorption, iron recycling by macrophages, and iron mobilization from hepatic stores. On the molecular level, ferroportin, an iron export protein at the basolateral membrane of the enterocyte, macrophages and hepatocytes, is internalized and lysosomal degraded under the influence of hepcidin. The synthesis of hepcidin is modulated by iron status, hypoxia, and inflammation [12-14].

\section{Causes}

Iron deficiency results when either dietary intake does not meet the body's requirement or when there is chronic blood loss. These two causes together with malabsorption, account for the majority of cases. A list of the all causes of IDA is given in Table I. The likely cause of IDA vary with the age. The prevalence of IDA exhibit two peaks. The first peak occurs during infancy and early childhood due to rapid growth and exudative enteropathy due to cow's milk. The second peak is seen during adolescents and adults due to blood loss and intestinal causes [4,5].

The dietary iron requirement for adult is estimated at $55 \mathrm{mg} / \mathrm{kg}$ and is higher in infants and young children due to their rapid growth. Inadequate dietary iron intake occurs in infants due to the low concentration of iron in milk. Human breast milk and cows milk have low iron content, but the bioavailability of iron in human milk is greater. Infants are particularly prone to developing IDA due to lower body iron stores, larger requirements, and decreased intake from a milk based diet [15].

\begin{tabular}{|c|c|c|}
\hline & Cause & Due to \\
\hline \multirow{3}{*}{$\begin{array}{l}\text { Intestinal } \\
\text { absorption } \\
\text { defects }\end{array}$} & Inadequate absorption & $\begin{array}{l}\left.\text { Poor bioavailability (Heme } \mathrm{Fe}>\mathrm{Fe}^{+2}>\mathrm{Fe}^{+3}\right) \text {, antiacid therapy, tannins, phytates, } \\
\text { phosphates, other metals }(\mathrm{Co}, \mathrm{Pb})\end{array}$ \\
\hline & Impaired absorption & $\begin{array}{l}\text { Inflammatory bowel disease, celiac disease, postgastrectomy, Helicobacter } \\
\text { Pilori infection, prolonged diarrhea }\end{array}$ \\
\hline & Dietary factors & Excessive cow's milk, vegetarian diet \\
\hline \multirow[t]{4}{*}{ Blood loss } & Intestinal loss & $\begin{array}{l}\text { Epistaxis, ulcer, Meckel's diverticulum, milk-induced enteropathy, parasitosis, } \\
\text { variceal, tumor or polyps, inflammatory bowel disease, arteriovenous } \\
\text { malformation, aspirin, steroid }\end{array}$ \\
\hline & Pulmonary loss & $\begin{array}{l}\text { Pulmonary hemosiderosis, tuberculosis } \\
\text { Goodpasture syndrome, Ig A deficiency, bronchiectasis }\end{array}$ \\
\hline & Genitourinary loss & $\begin{array}{l}\text { Nephritic syndrome (loss of transferrin), Berger disease, intravascular hemolysis } \\
\text { (paroxysmal nocturnal hemoglobinuria), menstrual loss, tumor, dialysis }\end{array}$ \\
\hline & Hepatobiliary system & Hematobilia \\
\hline \multirow[t]{4}{*}{ Rare causes } & $\begin{array}{l}\text { Inadequate presentation } \\
\text { to erythroid precursors }\end{array}$ & $\begin{array}{l}\text { Atransferrinemia (autosomal recessive disorder, severe hypochromic microcytic } \\
\text { anemia with a low SI and SIBC), antitransferrin receptor antibodies }\end{array}$ \\
\hline & $\begin{array}{l}\text { Abnormal intracellular } \\
\text { transport/utilization }\end{array}$ & Erythroid iron trafficking defects (DMT-1 mutations), defects of heme synthesis \\
\hline & $\begin{array}{l}\text { Defects in intestinal iron } \\
\text { uptake }\end{array}$ & $\begin{array}{l}\text { Iron refractory iron deficient anemia - IRIDA (severe hypochromic microcytic } \\
\text { anemia with a low SI and high SIBC and normal ferritin) }\end{array}$ \\
\hline & Increased demand & $\begin{array}{l}\text { Rapid growth (low birth weight, prematurity, twins, puberty, pregnancy), } \\
\text { cyanotic congenital hearth disease }\end{array}$ \\
\hline
\end{tabular}

Table I. Causes of iron deficiency anemia 
During acute blood loss, body iron stores are generally sufficient for accelerated erythropoiesis and subsequent iron uptake is adequate for restoring iron homeostasis. IDA only develops over weeks to months of chronic or recurrent blood loss. Causes of chronic blood loss include excessive menstrual bleedings (menorrhagia), gastrointestinal (GIS) hemorrhage, hematuria and recurrent epistaxis. GIS bleeding result from primary GIS disease including benign or malignant neoplasm, ulceration, esophageal variceal, inflammatory bowel diseases, parasitic infections, arteriovenous malformations, bezoar, drugs such as nonsteroidal anti-inflammatory agents and steroids. Coagulopathy due to renal and hepatic diseases and inherited bleeding disorders are frequently associated with IDA [16-19].

IDA can be induced iatrogenically through excessive phlebotomies of blood donor, as a regular blood donation of $450 \mathrm{ml}$ removes approximately $200 \mathrm{mg}$ of iron from the body [20]. Finally, rare genetic defects in ferroportin and hepcidin regulation have been reported to cause iron refractory iron deficiency anemia (IRIDA) in humans [21].

\section{Clinical features}

Characteristic clinical features of IDA in hematologic, intestinal, neurologic, cardiac, muscular and immunologic systems are summarized in Table II.

There are considerable variations in clinical manifestations, making early diagnosis challenging. Early diagnosis is possible only through IDA screening strategies, enabling the detection of presymptomatic patients. Early detection in infancy or young children is important allowing iron treatment that may result in normal mental motor development and present irreversible disability [22,23]. Clinical and laboratory signs are highly polymorphic and of varying severity, ranging from milder conditions, such as the pallor and isolated anomalies of microcytosis and hypochromic erythrocytes, to severe disorders, including neurocognitive impairment and intestinal epithelial changes. However, clinical signs solely due to anemia do not occur until anemia is severe, and can include lethargy, decreased exercise tolerance, weakness, weight loss, growth retardation, and generalized malaise. While these signs are typical for any anemia, the development of pica is unique to IDA. Evidence of blood loss, such as melena, hematuria, or bleeding from other sites may be noted at the time of physical examination [24-29].

\begin{tabular}{|c|c|c|}
\hline System & Mechanism & Clinical features \\
\hline Intestinal & Epithelial changes and bleeding & $\begin{array}{l}\text { Angular stomatitis, glossitis, dysphagia, esophageal web (Plummer } \\
\text { Vinson syndrome), koilonychia, exudative enteropathy, Pica } \\
\text { (bezoar), malabsorption syndrome, melena or hematochezia }\end{array}$ \\
\hline Neurologic & Impair neurotransmitter mechanism & $\begin{array}{l}\text { Reduced neurocognitive performance, lower mental and motor } \\
\text { developmental test scores on the Bayley Scale, breath holding } \\
\text { spells, lethargy, irritability }\end{array}$ \\
\hline Cardiac & Increase in plasma volume & Arrhythmia, and a systolic heart murmur \\
\hline Muscular & $\begin{array}{l}\text { Deficiency of myoglobin and } \\
\text { cytochrome } C\end{array}$ & Decreased exercise tolerance, weakness, generalized malaise \\
\hline Immunologic & Impaired leukocyte formation & Increased susceptibility to infection in iron deficiency \\
\hline Hematologic & $\begin{array}{l}\text { Decreased heme production, } \\
\text { reduction in iron dependent enzymes }\end{array}$ & Nonspecific symptoms (pallor, weakness), splenomegaly \\
\hline
\end{tabular}

Table II. Major clinical manifestations of iron deficiency anemia 
The diagnostic approach to IDA including identifying the underlying disease trigger with a through history, physical examination, and laboratory investigations. A detailed history of dietary intake, iron supplementation in infancy and lactation, and blood loss should be assessed. Standard laboratory tests for diagnosis of IDA include complete blood count with reticulocyte count and blood smear, and levels of serum iron, total iron binding capacity and ferritin [30]. Iron status at different phases of the disease are summarized in Table III.

Further tests including hemoglobin electrophoresis, urinalysis, fecal occult blood test, coagulation parameters, serum biochemistry, endoscopy and abdominal imaging may be required in confirming the diagnosis and /or excluding other causes of microcytic anemia [6-10].

\section{Complete blood count and blood smear}

Anemia is defined as a hemoglobin concentration, below the normal range for age and gender. Red cell indices MCV (mean corpuscular volume), $\mathrm{MCH}$ (mean corpuscular hemoglobin) and MCHC (mean corpuscular hemoglobin concentration) are lower than normal

Phases Laboratory changes

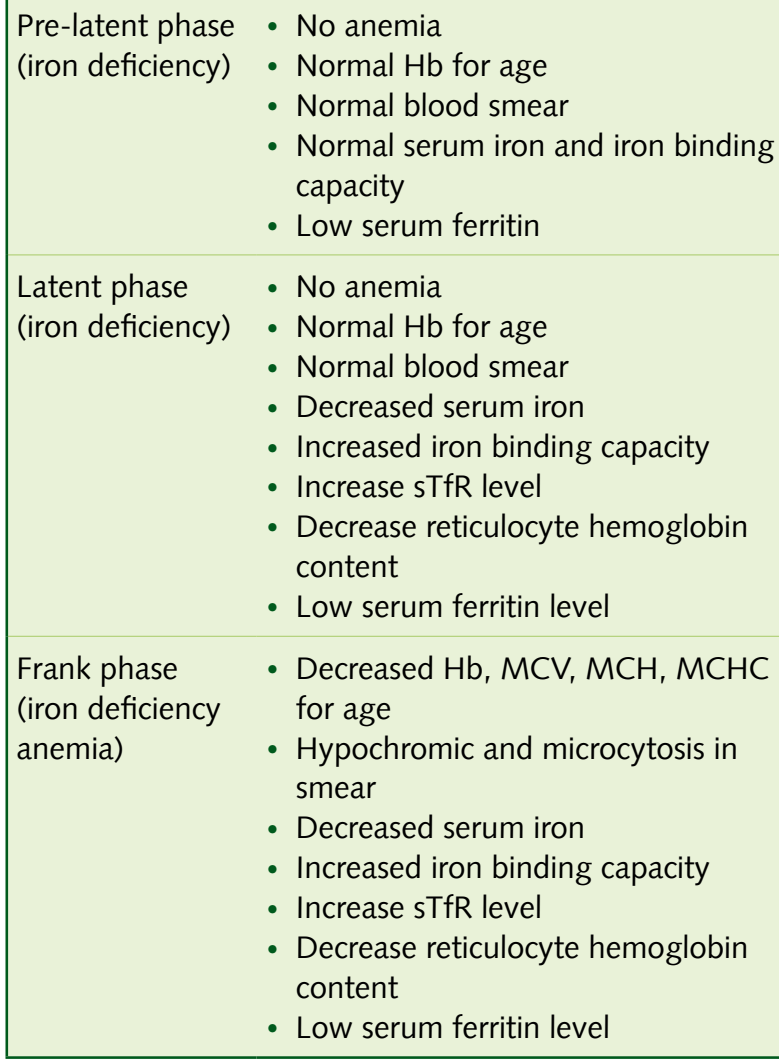

Table III. Three phases of iron deficiency anemia

$\mathrm{MCH}=$ mean corpuscular hemoglobin;

$\mathrm{MCHC}=$ mean corpuscular hemoglobin

concentration; $\mathrm{MCV}=$ mean corpuscular volume values for age [31]. Elevated red cell distribu-

tion width (RDW) is useful for discriminating from thalassemia minor. Red cell morphology shows hypochromia microcytosis and anisocytosis. Platelet count is usually elevated, particularly in patients with chronic blood loss, exceeding $1 \times 10^{6} / \mu \mathrm{l}$ in some cases. Occasionally, neutropenia due to decreased neutrophil production can occur in IDA.

\section{Serum iron concentration}

Typically, it is very low in patients with IDA. However, mildly low to low normal serum iron values can also be observed with anemia of inflammatory disease. Serum iron can be transiently elevated by intravascular red blood cell lysis, recent blood transfusion, and iron supplementation, which can complicate interpretation of laboratory data [32].

\section{Total iron binding capacity}

It is a measure of the plasma iron concentration that can be bound by plasma transferrin. Iron saturation reflects the amount of plasma iron bound the transferrin and is low $(<20 \%)$ in cases of IDA [32]. 


\section{Ferritin}

Serum level of ferritin correlates well with body iron stores. It is decreased in IDA and increased in iron overload. Ferritin is also an acute phase protein, and hyperferritinemia can occur with underlying disease, such as inflammatory disease, neoplasia, liver diseases. Nevertheless, low serum ferritin concentrations $(<12 \mathrm{ng} / \mathrm{ml})$ can be helpful in differentiating IDA from anemia of inflammatory disease [32].

\section{Bone marrow iron}

Body iron stores can be qualitatively assessed by staining bone marrow with prussian blue stain. Low bone marrow iron content is informative but invasive investigation. Thus, bone marrow iron remain the gold standard for diagnosis of IDA in difficult cases.

\section{Serum transferrin receptor level (STfR)}

Recent data indicate that sTfR can assess iron status better than previously used conventional laboratory tests. Plasma sTfR levels increase with iron deficiency anemia. Thus, sTfR levels may be a useful parameter for distinquishing between anemia of chronic disease and IDA but not widely available $[33,34]$.

\section{Reticulocyte hemoglobin content $(\mathrm{CHr})$ and percentage of hypochromic cells (\% Hypo)}

Increased percentage of hypochromic erytrocytes and a reduced hemoglobin content of reticulocytes are found in functional iron deficiency. They are useful parameters to evaluate erythropoietic activity in functional iron deficiency [35].

\section{Serum hepcidin levels}

Few data are available on the evaluate of hepcidin in IDA. Previous studies indicate that hepcidin increases with iron overload and decreases with IDA [12-14].

\section{Tests for blood loss}

If melena or hematochezia is not evident and no blood loss can be identified, fecal occult blood tests should be performed. Various commercial tests are available to detect occult blood in stool that may not be visible on visual inspection. However, false positive results are possible with oral iron supplementation, meat diets, and much less likely dietary myoglobin, hemoglobin. In some cases, the serum total protein values are also low due to the concomitant loss of plasma. Abdominal imaging and endoscopy are recommended to visualize intestinal organs and to assess the gastrointestinal tract for evidence of ulceration, masses or vascular malformation $[18,19]$.

\section{Differential diagnosis}

The major differential diagnosis of IDA is thalassemia and chronic disease anemia [36]. Classically, chronic disease anemia is associated with low SI and SIBC and high or normal serum ferritin levels. In most cases the differentiation between IDA and thalassemia trait is not difficult. Because the red cell distribution width (RDW) is normal in patients with thalassemia trait but high in those with IDA. However, differentiation between IDA and thalassemia trait can sometimes be difficult, especially when they both exist. In patients whose MCV improves but does not return to normal after adequate iron therapy, thalassemia traits should be excluded with hemoglobin electrophoresis. 
The general principles of treating patients with IDA include preventing further blood loss, correcting the anemia if severe, initiating iron supplementation, and addressing the underlying disease. A blood transfusion may be necessary prior to receiving results from diagnostic evaluation if the patient is severely anemic and demonstrating signs of heart failure and hypoxia. Thus, blood transfusion are only indicated in cases of severe anemia with resulting tissue hypoxia, to stabilize a decompensated patient, or prior to performing general anesthesia and surgery on a patient with moderate and severe anemia. There are no specific guidelines that indicate when a transfusion is appropriate; clinical and laboratory assessments of the patient are used to make that decision [37,38].

Iron supplementation is generally needed to restore iron homeostasis and should be based on the degree of anemia, underlying pathology, red blood cell count, serum iron panel and erytrocyte morphology.

In stable patients, oral iron therapy is usually preferred over parenteral iron administration in patients due to its low cost and higher safety. Both ferrous and ferric forms are available but only the ferrous form is recommended due to superior absorption. Ferrous sulphate is used most frequently but ferrous gluconate and fumarate can also be used. Physician must be taken when determining the dosage to be administered, as published doses are expressed as either milligrams of iron salt or elemental iron. Ferrous sulfate in a dose of 3-6 mg/kg per day is given for one month and then followed by a maintenance treatment over 1 to 3 months to replenish body stores of iron. Peak reticulocytosis occurs between the fifth and tenth days followed by a significant rise more than $1 \mathrm{~g} / \mathrm{dl}$ in hemoglobin level occurs. One of the more common side effects of oral iron supplementation is intestinal irritation, which can be minimized by dividing the dose several times a day. Interaction with other drugs is recognized and should be avoided [39,40].

Parenteral forms of iron other than red blood cell products can be administered if oral iron is poorly tolerated or if severe bowel disease is demonstrated or if erythropoietin therapy is needed (e.g renal dialysis). Approximately $70 \%$ of the iron dextran is absorbed from the injection site within days following intramuscular administration. A small dose should be administrated first a hypersensitivity reactions can occur. Other side effects of intramuscular iron include local irritation and pain the injection site. A simple formula provided on the web page at http://www.infed.com/calcltor.htm. can be used to determine the replacement dose of iron dextran.

Intravenous (IV) iron particularly useful in patients under anticoagulant or antiplatelet agent in whom intramuscular injections are contraindicated. Several IV iron preparations are available including iron gluconate, iron hydroxide sucrose complex and iron dextran. Dosage of IV form ranges from 1-4 mg/ $\mathrm{kg}$ per week. In patients, an initial test dose is given, if no adverse effects are noted, the remainder of the dose is administered over several hours. Adverse reactions from rapid infusion can include hypotension, tachycardia, dyspnea, and anaphylactoid reactions. Several months of iron supplementation may be necessary for red blood cell parameters to return to normal, and thereby should be continued beyond normalization of red blood cell parameters as body iron stores take much longer to be replenished [41].

\section{Conclusion}

Iron is a vital element for multiple metabolic functions, most notably oxygen transport by hemoglobin. Iron homeostasis depends upon regulated absorption of iron by the enterocyte, a highly specialized cell of the duodenum that coordinates dietary iron uptake and transport into the body. IDA typically develops following dietary factors, blood loss and intestinal causes after iron stores have been exhausted. 
Although several iron parameters have been studied for the diagnosis of IDA, ferritin remains the most reliable marker of IDA. However, it must be remembered that ferritin is increased during inflammation and infections and may not be helpful to estimate the IDA from inflammatory conditions. Other authors have described "unconventional" markers such as hepcidin and sTfR, which have been used as research tools but not gained widespread acceptance in routine practice. With appropriate therapy, patients with IDA can have a good prognosis as long as the underlying disease can be addressed.

\section{The review in brief}

Clinical question Summarize the current knowledge on IDA, with a particular focus on iron metabolism in regard to its pathogenesis and clinical features as well as to its diagnosis and treatment

Type of review Narrative

Conclusions Although several iron parameters have been studied for the diagnosis of IDA, ferritin remains the most reliable marker of IDA. With appropriate therapy, patients with IDA can have a good prognosis as long as the underlying disease can be addressed.

\section{References}

1. World Health Organization, The Unites Nations Children's Fund, Unites Nations University. Iron deficiency anemia; assessment, prevention, and control. Available at: http://www.who.int/nutrition/publications/micronutrients/anaemia_iron_deficiency/en (Last accessed July, 2004)

2. Zimmermann MB, Hurrell RF. Nutritional iron deficiency. Lancet 2007; 370: 511-20; http://dx.doi. org/10.1016/S0140-6736(07)61235-5

3. Suskind DL. Nutritional deficiencies during normal growth. Pediatr Clin N Am 2009; 56: 1035-53; http://dx.doi.org/10.1016/j.pcl.2009.07.004

4. Lozoff B, Brittenham GM, Viteri FE, et al. Developmental deficits in iron deficient infants: effects of age and severity of iron lack. J Pediatr 1982; 101: 948-52; http://dx.doi.org/10.1016/S00223476(82)80016-4

5. Zlotkin S. Clinical nutrition: 8 . The role of nutrition in the prevention of iron deficiency anemia in infants, children and adolescents. CMAJ 2003; 168: 59-63

6. Johnson-WimbleyTD, Graham DY.Diagnosis and management of iron deficiency anemia in the 21st century. Therap Adv Gastroenterol 2011; 4: 177-84; http://dx.doi.org/10.1177/1756283X11398736

7. Green R. Anemias beyond B12 and iron deficiency: the buzz about other B's, elementary, and nonelementary problems. Hematology Am Soc Hematol Educ Program 2012; 2012: 492-8; http:// dx.doi.org/10.1182/asheducation-2012.1.492

8. Finch CA, Huebers HA. Iron metabolism. Clin Physiol Biochem 1986; 4: 5-10

9. Clark SF. Iron deficiency anemia. Nutr Clin Pract 2008; 23: 128-41; http://dx.doi. org/10.1177/0884533608314536

10. Bermejo F, Garcia Lopez S. A guide to diagnosis of iron deficiency and iron deficiency anemia in digestive diseases. World J Gastroenterol 2009; 15: 4638-43; http://dx.doi.org/10.3748/wjg.15.4638

11. Iolascon A, Camaschella C, Pospisilova D, et al. Natural history of recessive inheritance of DMT 1 mutations. J Pediatr 2008; 152: 136-9; http://dx.doi.org/10.1016/j.jpeds.2007.08.041

12. Kaya Z, Yildiz E, Gursel T, et al. Serum prohepcidin levels in children with solid tumors, inflammatory bowel disease and iron deficiency anemia. J Trop Pediatr 2011; 57: 120-5; http://dx.doi. org/10.1093/tropej/fmq058 
13. Rivera S, Nemeth E, Gabayan V, et al. Synthetic hepcidin causes rapid dose-dependent hypoferremia and is concentrated in ferroportin-containing organs. Blood 2005; 106: 2196-9; http://dx.doi. org/10.1182/blood-2005-04-1766

14. Ganz T, Nemeth E. Iron imports: IV. Hepcidin and regulation of body iron metabolism. Am J Physiol Gastrointest Liver Physiol 2006; 290: 199-203; http://dx.doi.org/10.1152/ajpgi.00412.2005

15. Griffin IJ, Abrams SA. Iron and breastfeeding. Pediatr Clin North Am 2001; 48: 401-13; http:// dx.doi.org/10.1016/S0031-3955(08)70033-6

16. Zhu A, Kaneshiro M, Kaunitz JD. Evaluation and treatment of iron deficiency anemia:A gastroenterological perspective. Dig Dis Sci 2010; 55: 548-59; http://dx.doi.org/10.1007/s10620-009-1108-6

17. Scholl TO. Maternal iron status: relation to fetal growth, length of gestation and iron endowment of the neonate. Nutr Rev 2011; 69: 23-9; http://dx.doi.org/10.1111/j.1753-4887.2011.00429.x

18. Majid S, Salih M, Wasaya R, et al. Predictors of gastrointestinal lesions on endoscopy in iron deficiency anemia without gastrointestinal symptoms. BMC Gastroenterol 2008; 8: 52; http://dx.doi. org/10.1186/1471-230X-8-52

19. Serefhanoğlu S, Büyükaşik Y, Emmungil H, et al. Identification of clinical and simple laboratory variables predicting responsible gastrointestinal lesions in patients with iron deficiency anemia. Int J Med Sci 2010; 8: 30-8

20. Finch CA, Cook JD, Labbe RF, et al. Effect of blood donation on iron stores as evaluated by serum ferritin. Blood 1977; 50: 441-7

21. Finberg KE, Heeney MM, Campagna DR, et al. Mutations in TMPRSS6 cause iron-refractory iron deficiency anemia (IRIDA). Nat Genet 2008; 40: 569-71; http://dx.doi.org/10.1038/ng.130

22. Biondich PG, Downs SM, Carroll AE, et al. Shortcomings in infant iron deficiency screening methods. Pediatrics 2006; 117: 290-4; http://dx.doi.org/10.1542/peds.2004-2103

23. Bogen DL, Duggan AK, Dover GJ, et al. Screening for iron deficiency anemia by dietary history in a high risk population. Pediatrics 2000; 105: 1254-9; http://dx.doi.org/10.1542/peds.105.6.1254

24. Lozoff B, Çorapci F, Burden MJ, et al. Preschool aged children with iron deficiency anemia show altered affect and behavior. J Nutr 2007; 137: 683-9

25. Oner N, Kaya Z, Türkyilmaz Z, et al. An unusual cause of iron deficiency anemia in a child with colonic lithobezoar: Case report and review of the literature. J Hematol 2012; 1: 28-31

26. Felt BT, Beard JL, Schallert T, et al. Persistent neurochemical and behavioral abnormalities in adulthood despite early iron supplementation for perinatal iron deficiency anemia in rats. Behav Brain Res 2006; 171: 261-70; http://dx.doi.org/10.1016/j.bbr.2006.04.001

27. Akman M, Cebeci S, Okur V, et al. The effects of iron deficiency on infants developmental test performance. Acta Paediatr 2004; 93: 1391-6; http://dx.doi.org/10.1111/j.1651-2227.2004.tb02941.x

28. Ortiz E, Pasquini JM, Thompson K, et al. Effect of manipulation of iron storage, transport, or availability on myelin composition and brain iron content in three different animal models. J Neurosci Res 2004; 77: 681-9; http://dx.doi.org/10.1002/jnr.20207

29. Grantham-McGregor S, Ani C. A review of studies on the effect of iron deficiency on cognitive development in children. J Nutr 2001; 131: 649-66S

30. Urrechaga E, Borque L, Escanero JF. Erythrocyte and reticulocyte parameters in iron deficiency and thalassemia. J Clin Lab Anal 2011: 25: 223-8; http://dx.doi.org/10.1002/jcla.20462

31. Dallman PR, Siimes MA. Percentile curves for hemoglobin and red cell volume in infancy and childhood. J Pediatr 1979; 94: 26-31; http://dx.doi.org/10.1016/S0022-3476(79)80344-3

32. Koerper MA, Dallman PR. Serum iron concentration and transferrin saturation in the diagnosis of iron deficiency in children: normal developmental changes. J Pediatr 1977; 91: 870-4; http:// dx.doi.org/10.1016/S0022-3476(77)80879-2

33. Olivares $\mathrm{M}$, Walter $\mathrm{T}$, Cook JD, et al. Usefulness of serum transferrin receptor and serum ferritin in diagnosis of iron deficiency in infancy. Am J Clin Nutr 2000; 72: 1191-5 
34. Punnonen K, Irjala K, Rajamaki A. Serum transferin receptor and its ratio to serum ferritin in the diagnosis of iron deficiency. Blood 1997; 89: 1052-7

35. Brugnara C, Laufer MR, Friedman AJ, et al. Reticulocyte hemoglobin content(CHr):early indicator of iron deficiency and response to therapy. Blood 1994; 83: 3100-1

36. Dallman PR, Yip R, Oski FA. Iron deficiency and related nutritional anemias. In: Nathan DG, Oski $\mathrm{Fa}$ (eds) Hematology in infancy and childhood. Philadelphia: Saunders, 1993

37. Chaparro CM. Setting the stage for child health and development: prevention of iron deficiency in early infancy. J Nutr 2008; 138: 2529-33

38. Grant CC, Wall CR, Brewster D, et al. Policy statement on iron deficiency in preschool aged children. J Paediatr Child Health 2007; 43: 513-21; http://dx.doi.org/10.1111/j.1440-1754.2007.01128.x

39. Bopche AV, Dwivedi R, Mishra R, et al. Ferrous sulphate versus iron polymaltose for treatment of iron deficiency anemia in children. Ndian Pediatr 2009; 46: 883-5

40. Cogswell ME, Parvanta I, Ickes L, et al. Iron supplementation during pregnancy, anemia, and birth weight: a randomized controlled trial. Am J Clin Nutr 2003; 78: 773-81

41. Fishbane S, Kowalski EA. The comparative safety of intravenous iron dextran, iron saccharate, and sodium ferric gluconate. Semin Dial 2000; 13: 381-4; http://dx.doi.org/10.1046/j.1525139x.2000.00104.x 